\title{
Can providing shade at water points help Kalahari birds beat the heat?
}

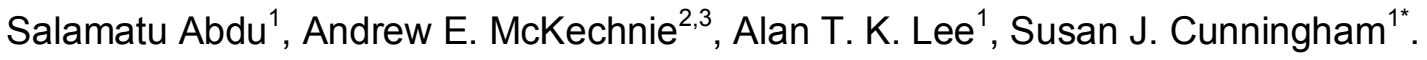

${ }^{1}$ FitzPatrick Institute of African Ornithology, DST-NRF Centre of Excellence, University of Cape Town, Private Bag X3, Rondebosch 7701, South Africa

${ }^{2}$ DST-NRF Centre of Excellence at the Percy FitzPatrick Institute, Department of Zoology and Entomology, University of Pretoria, Pretoria 0002, South Africa

${ }^{3}$ South African Research Chair in Conservation Physiology, National Zoological Gardens of South Africa, P.O. Box 754, Pretoria 0001, South Africa

*corresponding author: susie.j.c@gmail.com

\section{Abstract:}

Arid-zone birds trade-off dehydration and hyperthermia during hot weather, as they are dependent on evaporative cooling when air temperature approaches or exceeds body temperature. Water points in many arid ecosystems become surrounded by piospheres, exposing drinking birds to high radiant heat loads and exacerbating this trade-off. This challenge will be aggravated under climate warming. One possible mitigation approach is to reduce heat loads birds experience when seeking water. We experimentally shaded water points on farmland in the Kalahari. We used a Before-After Control-Impact design to assess the impact of artificial shade on species, visitation rates and visitation patterns of drinking birds. The number of species drinking was not affected by the introduction of shade, but overall visitation rates declined, despite a habituation period prior to data collection and increased use of shaded water points during the heat of the day. Of the ten most common species, one -the smallest species in the study - significantly increased and four significantly reduced visitation rates to experimentally shaded water points. Providing shade benefited few species overall, perhaps because of increased predation risk. Future work should investigate the impacts of shader design in order to develop this method as a conservation tool.

\section{Keywords}

$\mathrm{BACl}$; climate change; dehydration; hyperthermia; piosphere; temperature. 


\section{Introduction}

Water resources determine many aspects of avian behaviour and ecology in desert environments, and the distributions of arid-zone birds are often strongly linked to water sources (Fisher et al. 1972; Cade 1965; Maclean 1996; Davies et al. 2010). The interactions between desert birds and drinking water sources involve a number of important trade-offs. One is a trade-off between hydration status and energy conservation; taxa such as sandgrouse (Pterocliformes) travel considerable distances each day to drink at water holes (Maclean 1983; Maclean 1996), thereby substantially increasing daily energy requirements. Another involves predation risk, because in arid environments predators often aggregate in the vicinity of waterholes (Fisher et al. 1972; Ferns \& Hinsley 1995; Cade 1965).

An additional trade-off that may significantly influence drinking behaviour in arid-zone birds, but which has received far less attention than the two mentioned above, concerns the thermal environment birds experience while drinking. Most waterholes are fully exposed to sun, and on account of heavy use by large mammals are usually surrounded by bare areas with little or no vegetation (piospheres; James et al. 1999). The solar heat load associated with the absence of shade means that drinking birds experience environmental temperatures (a measure of the integrated heatload experienced by the animal, accounting for factors such as solar radiation and wind in addition to air temperature; Bakken, 1976; Robinson et al., 1976) far above air temperature, particularly if they drink during the hottest part of the day. In many deserts, air temperatures routinely exceed avian body temperature $\left(\sim 40-42^{\circ} \mathrm{C}\right)$, with the result that operative temperatures in full sunlight at midday may approach or even exceed $60^{\circ} \mathrm{C}$ (Wolf \& Walsberg 1996). Wolf and Walsberg (1996), for instance, estimated that in the absence of wind, the operative temperature experienced by a $7-g$ verdin (Auriparus flaviceps) in the Sonoran Desert increases by at least $12{ }^{\circ} \mathrm{C}$ if the bird moves from a completely shaded perch into full sun.

The notion that birds drinking at waterholes may be exposing themselves to operative temperatures high enough to pose a severe risk of lethal hyperthermia is supported by recent data on avian heat tolerance limits. Studies in the Kalahari desert of southern Africa reveal that the maximum air temperatures tolerated by three ploceid passerines during acute (10-30 $\mathrm{min}$ ) heat exposure under laboratory conditions ranged from $48{ }^{\circ} \mathrm{C}$ in the $10 \mathrm{~g}$ scalyfeathered finch (Sporopipes squamifrons) to $54^{\circ} \mathrm{C}$ in the $40-\mathrm{g}$ white-browed sparrow-weaver (Plocepasser mahali) (Whitfield et al. 2015). Wolf and Walsberg's (1996) estimates of the effect of solar radiation on operative temperatures in verdins is likely applicable to scalyfeathered finches, on account of their similar body mass. If operative temperature is also $\sim 12{ }^{\circ} \mathrm{C}$ higher in full sunlight compared to shade for a small bird in the Kalahari, scaly- 
feathered finches drinking in full sun when air temperature is $40-45^{\circ} \mathrm{C}$ likely face a severe risk of lethal hyperthermia, since estimated operative temperature $\left(\sim 52-57^{\circ} \mathrm{C}\right)$ will be well above their heat tolerance limit $\left(48^{\circ} \mathrm{C}\right)$.

Trade-offs between dehydration and hyperthermia risk in birds reliant on waterholes in arid landscapes will become more pronounced under future climates. Increases in maximum air temperatures, as well as more frequent and longer heat waves (IPCC 2007; IPCC 2011) will result in large increases in water requirements for evaporative cooling (Mckechnie \& Wolf 2010; Albright et al. 2017), as well as higher operative temperatures when drinking. Consequently, the microclimates experienced by arid-zone birds while drinking, and the possibility of manipulating those microclimates in order to reduce thermal stress, are of considerable interest in the context of the conservation and management of arid-zone bird communities.

We hypothesized that experimental moderation of the operative temperatures experienced by birds drinking at desert waterholes should reduce the severity of trade-offs arising from the high operative temperatures associated with this behaviour. If Kalahari birds are restricted in their ability to access water primarily due to high radiant heat loads, then provision of artificial shade may:

(a) Allow species that normally drink only at cooler times of day (morning) to access water throughout the day;

(b) Allow more species and/or larger numbers of individuals to drink during hot weather;

(c) Benefit smaller birds more than larger birds: small species have higher surface area - volume ratios, higher mass-specific rates of solar heat gain, and consequently a larger increment in operative temperature when they move from shade into the sun (Bakken 1976, Robinson et al. 1976).

\section{Methods}

\subsection{Study site}

The study was conducted in October and November 2014 on a privately-owned sheep and beef farm (Murray Guest Farm, 26 59'S, 20 52'E) within arid-savanna habitat in the southern Kalahari, Northern Cape province of South Africa. Diurnal air temperatures in this arid zone average $\sim 35^{\circ} \mathrm{C}$ and maximum daily temperatures often exceed $40^{\circ} \mathrm{C}$ during summer (October - April; Kruger and Shongwe 2004). The area is characterized by sparse, 
arid savannas on deep red sands and immobile dunes with a relatively low relief (Perkins and Thomas 1993). Rainfall is erratic and unpredictable with $100-400 \mathrm{~mm}$ per year occurring predominantly during summer (Lovegrove 1993). Air temperature (at $2 \mathrm{~m}$ off the ground) and rainfall were measured at ten-minute intervals during the course of the study using a portable weather station (Vantage Pro2, Davis Instruments, Hayward, CA), set up centrally within the study area.

\subsection{Experimental design}

Time constraints precluded a balanced design, therefore a before-after control-impact (BACl) experimental design (Green 1979; Skalski and Robson 1992) was employed to test the effect of artificial shade at water points on the numbers, timing and diversity of birds drinking. A significant interaction between experimental phase ("before" and "after") and treatment group ("control" and "impact") on the response variable suggests that changes at the "impacted" sites during the "after" period are likely to be due to effects of the impact itself (in our case, artificial shading) rather than to any background factor (e.g. changes in temperature and rainfall as the season progressed) that could be expected to affect all sites equally.

We chose six artificial stock water points that were already in place on the farm for the experiment. These comprised long, narrow troughs $(\sim 200-300 \mathrm{~cm}$ long $\times 20-50 \mathrm{~cm}$ wide and $\sim 20-50 \mathrm{~cm}$ high) constructed from thick moulded plastic or metal and constantly supplied with water sourced from a borehole on the farm. All six water points were located within a $3 \mathrm{~km}$ radius: four within the Kalahari dunefield, and two near the edge of the dry Kuruman River bed. Water points were chosen based on stock rotation practices of the farmers, to ensure cattle would not be present in the camps in which we were working during the course of the study. After suitable water points had been identified, these were organized into three 'pairs' based on distance from the river bed and our initial impressions of the numbers of birds visiting each. One of each water point per pair was then assigned at random to the control (unshaded throughout the study) or treatment group (shaded during the latter half of the experiment; see below).

Open wooden frames constructed of thin wooden poles $(3 \mathrm{~m} \times 2 \mathrm{~m}$ and raised $1.5 \mathrm{~m}$ above the ground on six $5 \mathrm{~cm}$-diameter poles) were erected over all six water points six days before the beginning of the experiment, to allow the bird community to habituate to their presence. These provided the framework to support a shade-cloth canopy in the second phase of the experiment, but cast negligible shade themselves (Figure A1). Data collection for the "before" phase of the experiment (hereafter Phase A) began on $14^{\text {th }}$ October 2014 and ran for 10 days. During this time all water points were left unshaded. At the end of this 
period, a heavy-weight dark blue shade-cloth was stapled across the top of the frames above the three water points in the "treatment" group, blocking approximately $80 \%$ of solar radiation. A period of six days was allowed for birds to habituate to the changed situation, after which a further six days of data were collected for the "after" phase of the experiment (hereafter Phase B).

\subsection{Data collection}

Data on bird visitation rates to water points were collected using programmable, highresolution LTL Acorn 5310WMG $940 \mathrm{~nm}$ MMS camera traps set on posts $\sim 1 \mathrm{~m}$ high at a distance of $\sim 5 \mathrm{~m}$ from at each water point. These cameras were programmed to take pictures of the water troughs every minute from 6:00 until 19:00, and the number and species of birds visiting were extracted from the photographs by counting birds visible on the sides of the trough in each photo and assigning these to species. We converted the number of birds counted to a visitation rate per hour, to account for the fact we could not identify individuals. This was calculated by dividing the total number of bird visits by the total number of hours recorded for each species. Only birds perched on the edge of the water troughs themselves were counted to avoid including birds just passing through but not intending to drink. Five sampling periods of one hour each (6:00-7:00 [early morning], 9:00-10:00 [late morning], 12:00-13:00 [early afternoon], 15:00-16:00 [late afternoon] and 18:00-19:00 [evening]) were chosen for data extraction; to assess patterns of water use over the course of the day and maximize the range of air temperatures sampled (Figure 1).

\subsection{Species recorded}

A total 43,507 bird visits to water points by 36 species were recorded during the course of the experiment (Table A1). Of these, ten resident species were recorded more than 350 times (Table 1). These species were included in species-specific analyses of the effect of providing shade on rates of use of water points.

Table 1: Ten most common species drinking at water points during the course of the experiment, including body mass of each species and number of bird-visits to water points recorded.

\begin{tabular}{|c|c|c|}
\hline Species & Body mass & $\begin{array}{l}\text { Bird-visits } \\
\text { recorded }\end{array}$ \\
\hline Sociable weaver Philetairus socius & $27.4 \mathrm{~g}$ & 17106 \\
\hline Cape turtle dove Streptopelia capicola & $130.3 \mathrm{~g}$ & 4929 \\
\hline Cape glossy starling Lamprotornis nitens & $82.5 \mathrm{~g}$ & 4588 \\
\hline Red-headed finch Amadina erythrocephala & $22.7 \mathrm{~g}$ & 4558 \\
\hline Southern grey-headed sparrow Passer diffuses & $24.7 \mathrm{~g}$ & 4114 \\
\hline Laughing dove Spilopelia senegalensis & $98.8 \mathrm{~g}$ & 2267 \\
\hline
\end{tabular}




\begin{tabular}{lrr}
\hline Black-throated canary Crithagra atrogularis & $12.7 \mathrm{~g}$ & 1077 \\
Namaqua dove Oena capensis & $39.9 \mathrm{~g}$ & 469 \\
Violet-eared waxbill Uraeginthus granatinus & $11.8 \mathrm{~g}$ & 419 \\
White-browed sparrow-weaver Plocepasser mahali & $47.5 \mathrm{~g}$ & 372 \\
\hline
\end{tabular}

\subsection{Daily patterns of use of water}

We used G-tests (making use of the Chi-squared distribution; Dytham 2003) to test for differences in the time of day at which the greatest proportion of birds visited control and experimental water points during Phase A and Phase B of the experiment; both overall and on a species-specific basis for the species in Table 1.

We compared patterns of visitation by birds between control and experimental water points during Phase $A$ and during Phase $B$. We also looked at whether visitation patterns changed between Phase $A$ and Phase $B$ at both control and experimental water points. As this amounted to four G-tests per species plus a further four tests for all species combined (44 tests in total), we applied a Bonferroni correction and set statistical significance at $p<0.001$ $(=0.05 / 44)$.

\subsection{Species richness and overall visitation rates}

Species richness (number of species visiting each water point) and overall bird visitation rates were analysed using GLMMs with Poisson error distribution (for count data) and a loglink function. All models included the random variables water point nested within pair, date and hour. We checked for overdispersion by comparing the residual deviance to the residual degrees of freedom. If a model was overdispersed, an observation level random effect, where each observation is assigned a unique code, was used to reduce any bias in parameter estimates or standard errors (Hilbe, 2011; Harrison, 2014). Fixed factors included in each model were treatment group (control or experimental), experimental phase (Phase A, prior to shading experimental water points; Phase $B$, artificial shade added at experimental water points only), and the interaction between treatment group and experimental phase. If this interaction term was significant, we could infer a change in species richness or visitation rate that was attributable to the addition of artificial shade. For models of changes in overall species richness and visitation rate of all species combined (two models in total), we set statistical significance at the standard $p=0.05$. Across the ten species-specific visitation rate models for the species in Table 1, we applied a Bonferroni correction for multiple tests, and set statistical significance at $p=0.005(=0.05 / 10)$. 


\section{Results}

\subsection{Temperature patterns}

Diurnal air temperatures ranged from $5.3^{\circ} \mathrm{C}$ (early morning) to $39.2^{\circ} \mathrm{C}$ (late afternoon) during the course of the study, with hottest temperatures occurring in the late afternoon (15:00 16:00), and temperatures remaining high until dusk ( 19:00). Mean diurnal (6:00 - 19:00) air temperatures were similar in Phase $A$ (mean and standard deviation: $27.2 \pm 4.5^{\circ} \mathrm{C}$ ) and Phase $\mathrm{B}\left(27.2 \pm 4.1^{\circ} \mathrm{C}\right)$, as were daily temperature maxima (Phase $\mathrm{A}$, average daily maximum $33.2 \pm 5.3^{\circ} \mathrm{C}$, hottest day $=39.2^{\circ} \mathrm{C}$; Phase $\mathrm{B}$, average daily maximum $32.2 \pm$ $5.0^{\circ} \mathrm{C}$, hottest day $=38.4^{\circ} \mathrm{C}$ ). No rain was recorded during Phase $\mathrm{A}$, but a total of $8.6 \mathrm{~mm}$ of rain fell during Phase $B$, with the heaviest rainfall event totaling $2.0 \mathrm{~mm}$.

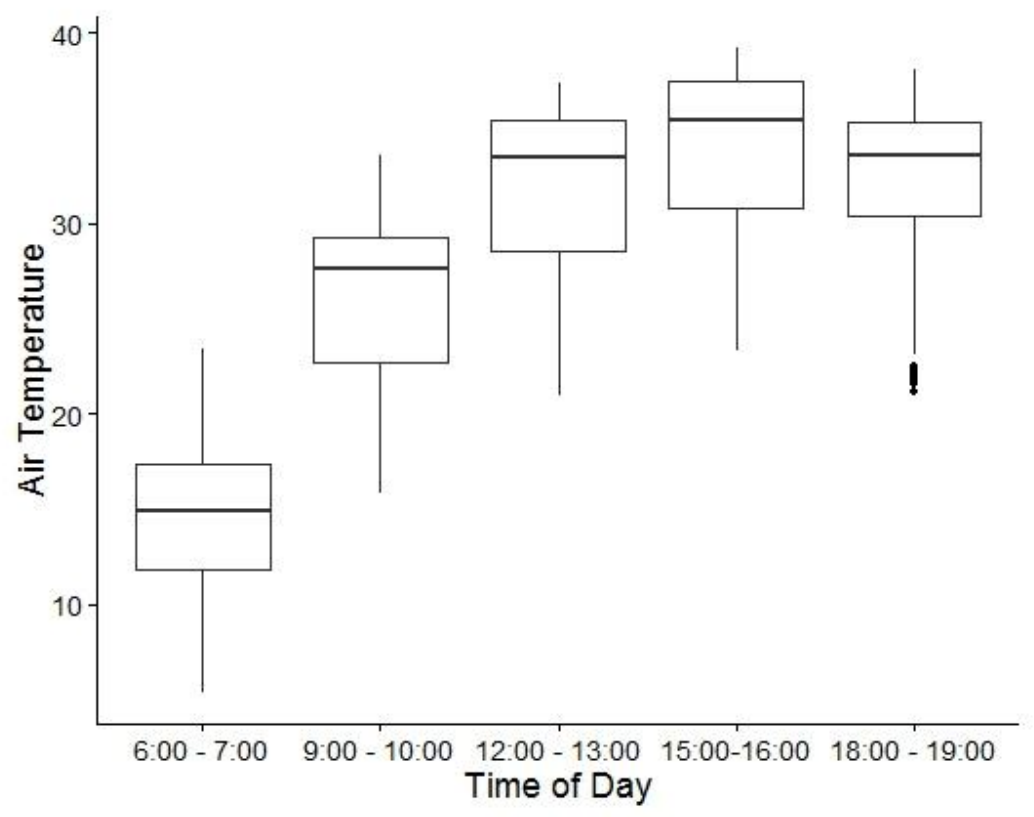

Figure 1: Diurnal air temperature patterns. Air temperature increased with time of day, peaking in the late afternoon (15:00-16:00). Temperatures remained high until dusk (19:00). Boxplots show median temperature (central line) and interquartile range (IQR; box edges). Whiskers show the temperature range, the 'outlier' dots at 18:00 - 19:00 are datapoints further than $1.5 \times$ IQR from the median.

\subsection{Water use patterns}

We found no difference in daily patterns of use of water by the drinking bird community as a whole between experimental and control water points in Phase $A$ of the experiment (no added shade) $X^{2}=3.24, p=0.52$ (Figure $2 A$ ). However, daily patterns of use of water by the 
bird community changed at both control and experimentally shaded water points between Phase $A$ and Phase $B$ of the experiment; $X^{2}=20.35, p<0.001$ and $X^{2}=45.34, p<0.001$, respectively (compare Figure $2 \mathrm{~A}$ with Figure $2 \mathrm{~B}$ ). At control water points, this change was characterised by an increased proportion of visits occurring in the evening (18:00 - 19:00) and a decline in the early morning (06:00 - 07:00) during Phase B. At experimentally shaded water points, however, proportional visitation rates declined in the early- (06:00 - 07:00) and late-morning (09:00 - 10:00), but increased in the early- (12:00-13:00) and late-afternoon (15:00-16:00), in line with our predictions. This resulted in a significant difference in patterns of use of water by the drinking bird community between control and experimentally shaded water points in Phase $B$ of the experiment, $X^{2}=33.09, p<0.001$, with proportional visitation rates being higher in early- and late-afternoon at shaded water points than control water points (Table A2, Figure 2B).

A

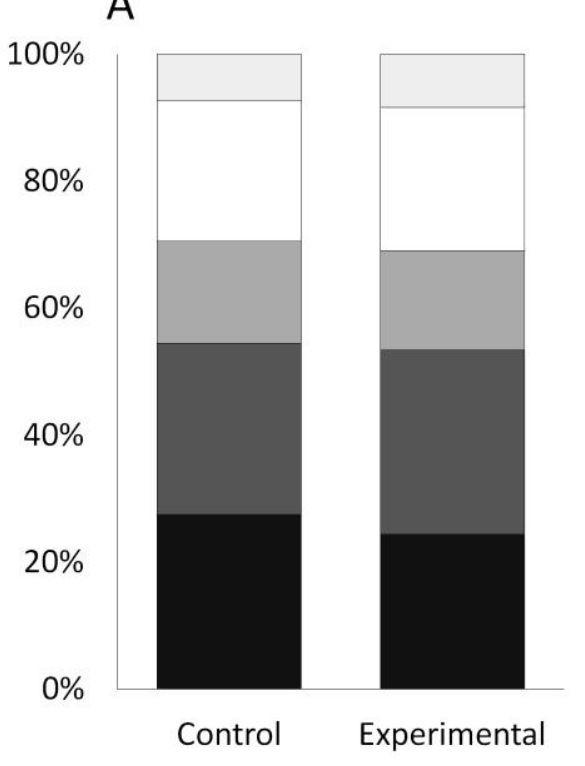

B

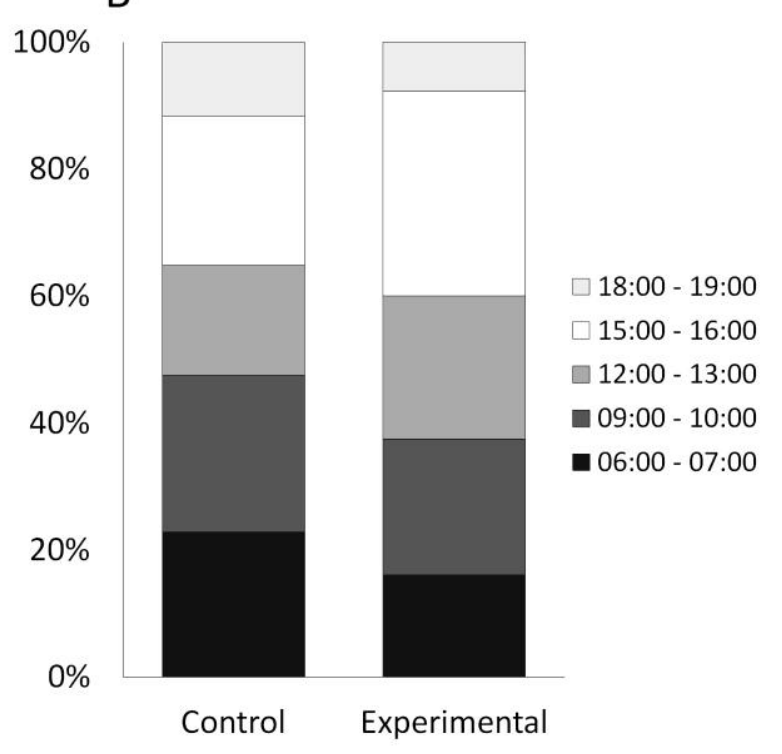

Figure 2: Diurnal patterns in visitation rates of birds to water points. Proportional visitation rates of birds at different hours of the day to control and experimental water points before (experimental Phase $A ; A$ ) and after artificial shade was added at experimental water points (experimental Phase B; B). (A) There was no difference in pattern of visitation to control vs experimental water points across the course of the day during Phase $A$ of the experiment, before artificial shade was added to experimental water points. (B) However, during Phase B of the experiment, proportional visitation rates were higher in early- and late-afternoon (12:00 -13:00 and 15:00-16:00, respectively) at experimentally shaded water points than at control water points.

Community-wide responses are often likely driven by the most common species present. However, of the ten most common species drinking at water points during this study (Table 1), only southern grey-headed sparrows significantly changed visitation patterns to 
experimental water points between Phases A and B (i.e. after shade was added). This species made up $9.5 \%$ of the total dataset, with 4114 bird-visits recorded. Southern greyheaded sparrows showed no significant difference in pattern of visitation when comparing experimental to control water points during either Phase A (no shade at either) or Phase B (shade provided at experimental water points only; all $p>0.001$ ). Despite this, they did change their pattern of visitation between Phase A and Phase $B$ within experimentallyshaded water points only. This manifested as an increase in the proportion of visits that occurred during the early- and late-afternoon at shaded water points during Phase $B$ (i.e. after shade was added) compared with the same water points during Phase $A$ (no shade, $X^{2}$ $=25.12, p<0.001$, Figure 3).

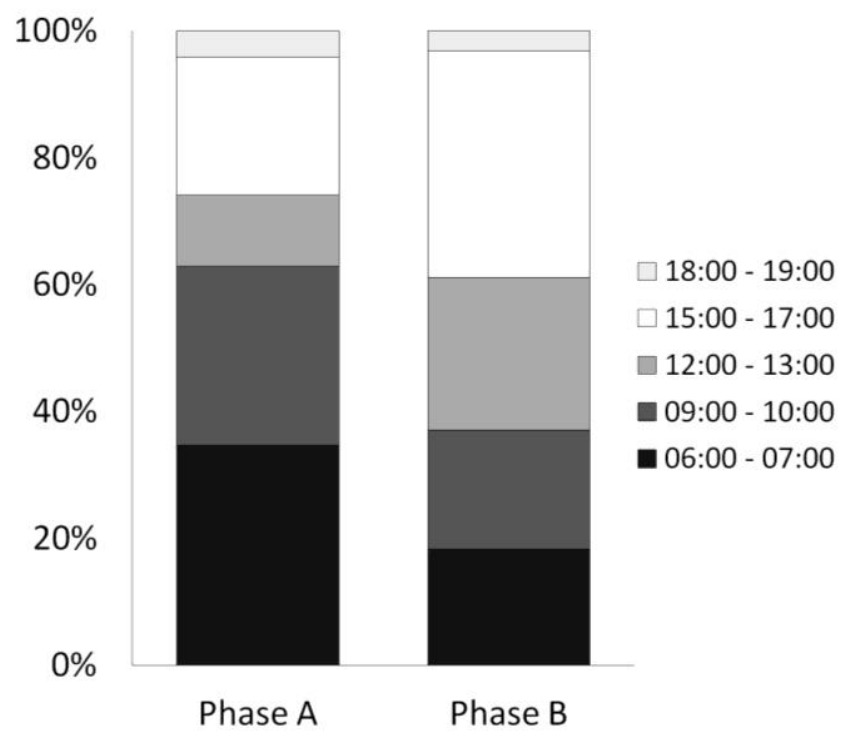

Figure 3: Patterns of visitation to water points by southern grey-headed sparrows. Patterns of visitation to experimental water points by southern grey-headed sparrows changed after the addition of artificial shade in Phase B of the experiment. A higher proportion of sparrow visits took place in the afternoon (12:00 - 13:00 and 15:00 -17:00) in Phase $B$ when shade was available, than in Phase $A$ when it was not.

\subsection{Species richness and overall water point use before and after addition of shade}

There was a significant negative interaction between treatment (experimental shade added vs control) and experimental phase (Phase A: before vs Phase B: after shading) on visitation rates of birds (all species combined) to water points. Visitation rates to experimentallyshaded water points were lower during Phase B (after shades were added), despite no parallel decline in rates of visitation to control water points (no shades added; Table 2, Figure 4A). 
Species richness remained constant at both control and shaded water points throughout the experiment (Table 2, Figure 4B).

Table 2: GLMM model outputs for the interaction between experiment phase (Phase A no shade vs Phase $B$ after shading half of the water points) and treatment (control vs shade added) on the number of species and visitations rates per hour of birds drinking at water points. Models fitted with Poisson error distribution; water point nested within pair and date included as random factors in the species richness model, water point nested within pair, date and hour as random factors in the visits per hour model. Estimates are not backtransformed. $\mathrm{N}=419$ hours of observations over 16 days (Phase A: 10 days, Phase B: 6 days) at 6 water points ( 3 control, 3 experimental).

\begin{tabular}{lllll}
\hline Response variable & Factor & Estimate \pm se & Z-statistic & P-value \\
\hline Mean bird visits per hour & Phase $(\mathrm{B})$ & $-0.08 \pm 0.25$ & -0.32 & 0.75 \\
\cline { 2 - 5 } & Treatment (shaded) & $-0.25 \pm 0.09$ & -2.90 & $0.004^{* *}$ \\
\cline { 2 - 5 } & Phase ${ }^{\star}$ treatment & $-0.26 \pm 0.13$ & -1.98 & $0.05^{*}$ \\
\hline \multirow{2}{*}{ Species richness } & Phase (B) & $0.14 \pm 0.09$ & 1.49 & 0.14 \\
\cline { 2 - 5 } & Treatment (shaded) & $0.11 \pm 0.08$ & 1.30 & 0.19 \\
\cline { 2 - 5 } & Phase*treatment & $-0.06 \pm 0.13$ & -0.46 & 0.65 \\
\hline
\end{tabular}
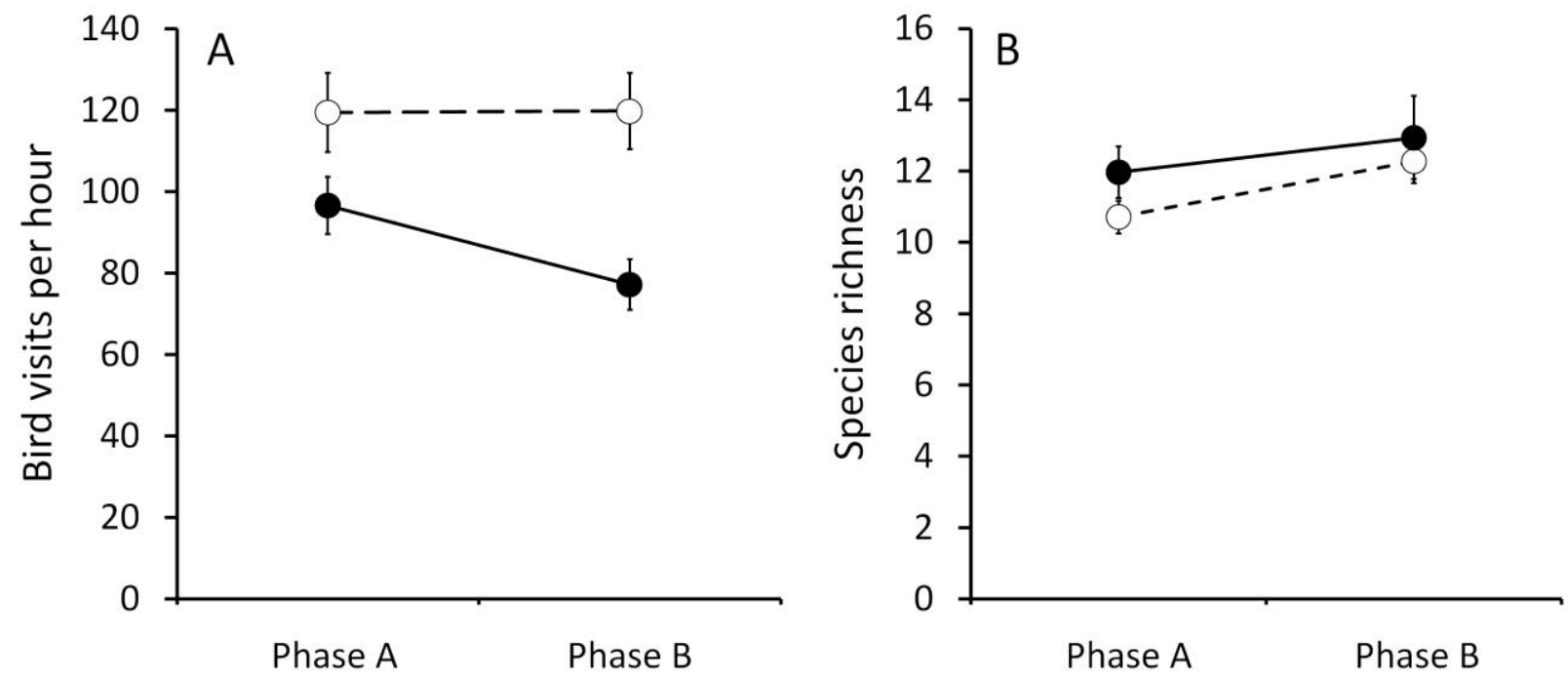

Figure 4: Changes in visitation rates and species richness in response to the addition of shade. $(A)$ visitation rates per hour and $(B)$ average number of species of birds drinking at water points before (Phase A) and after (Phase B) shade was added. Open circles and dashed lines indicate control water points (no shade added); filled circles and solid lines indicate experimental water points (shade added during Phase $\mathrm{B}$ ). Data are means \pm 1 standard error. $N=419$ hours of observations over 16 days (Phase A: 10 days, Phase B: 6 days) at 6 water points ( 3 control, 3 experimental). 
Of the ten most common species observed drinking during the course of the study, five significantly altered their overall visitation rates to water points in response to the addition of shade (i.e. showed a significant interaction between water point treatment group and experimental phase). Four of these species responded negatively to the introduction of shade, reducing visitation rates to shaded relative to control water points in Phase $B$ of the experiment: sociable weaver, cape turtle dove, Namaqua dove and white-browed sparrowweaver (Table 3, Figure 5 A-D). Only one species of these five species, the violet-eared waxbill (the smallest of our study species at $11.8 \mathrm{~g}$ ), responded positively to the addition of shade, increasing visitation rates to experimentally shaded relative to control water points in Phase $\mathrm{B}$ of the experiment (Table 3, Figure $5 \mathrm{~F}$ ). In addition, southern grey-headed sparrow and red-headed finch showed near-significant (significant at $p=0.05$ ) negative and positive responses, respectively, to the addition of shade (Table 3, Figure $5 \mathrm{E}$ and $\mathrm{G}$ ). 
Negative responders
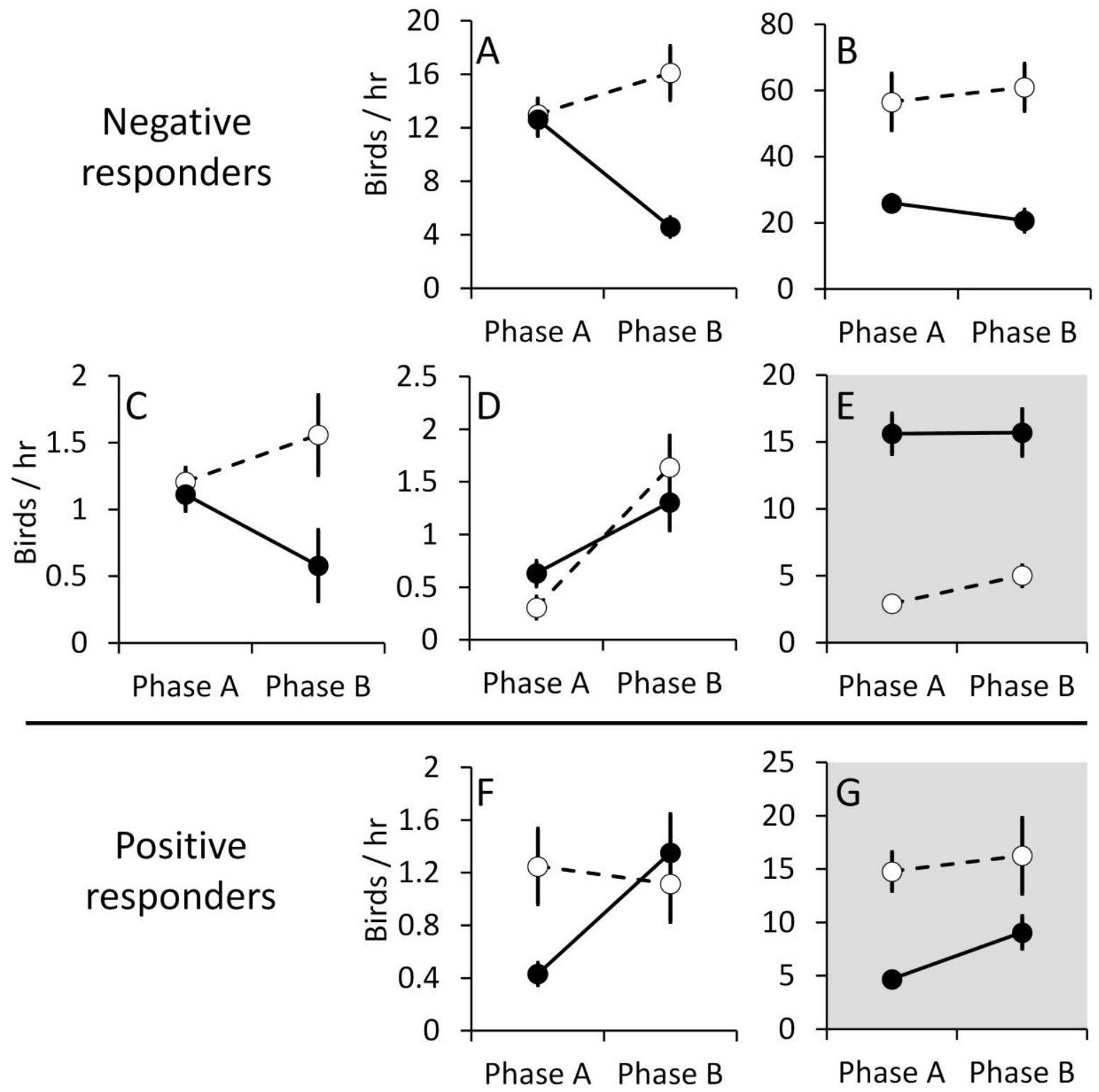

Figure 5: Species-specific changes in visitation rates in response to the addition of shade. Average visitation rates per hour of birds drinking at water points before and after shade was added, for species in which we detected a significant (white, all $p<0.005$ ) or near significant (grey, $p \leq 0.05$ ) interaction between experimental phase (A before vs $B$ after addition of shade at experimental water points) and treatment (experimental vs control water points): (A) cape turtle dove; (B) sociable weaver; (C) namaqua dove; (D) white-browed sparrowweaver; $(E)$ southern grey-headed sparrow; $(F)$ violet-eared waxbill; $(G)$ red-headed finch. Only violet-eared waxbills and red-headed finches increased visitation rates in response to the addition of shade (note that white-browed sparrow-weavers visited water points more frequently in general during Phase $B$, but increased visitation rates to control water points more than to shaded ones). Open circles and dashed lines indicate control water points (no shade added); filled circles and solid lines indicate experimental water points (shade added during Phase $B$ ). Data are means \pm 1 standard error. $N=419$ hours of observations over 16 days (Phase A: 10 days, Phase B: 6 days) at 6 water points ( 3 control, 3 experimental). 
Table 3: Model outputs for interactions between experiment phase (phase A no shade vs phase B after shading half of the water points) and treatment (control vs shade added) on the visitation rate (birds/hour) for ten bird species. Models were GLMMs with Poisson error distribution and water point nested within pair, date and hour included as random factors. Estimates are not back transformed. $\mathrm{N}=419$ hours of observations over 16 days (Phase $\mathrm{A}$ : 10 days, Phase B: 6 days) at 6 water points (3 control, 3 experimental). A Bonferroni correction for multiple tests was applied, and threshold for statistical significance set at $p=$ 0.005 .

\begin{tabular}{|c|c|c|c|c|}
\hline Species & Factor & $\begin{array}{l}\text { Estimate } \pm \\
\text { se }\end{array}$ & $\begin{array}{l}\text { Z- } \\
\text { statistic }\end{array}$ & P-value \\
\hline \multirow[t]{3}{*}{ Sociable weaver } & Phase (B) & $0.46 \pm 0.40$ & 1.16 & 0.25 \\
\hline & $\begin{array}{l}\text { Treatment } \\
\text { (shaded) }\end{array}$ & $-0.43 \pm 0.18$ & -2.45 & 0.01 \\
\hline & Phase ${ }^{\star}$ treatment & $-0.90 \pm 0.26$ & -3.46 & $0.001^{*}$ \\
\hline \multirow[t]{3}{*}{ Black-throated canary } & Phase (B) & $0.60 \pm 0.60$ & 1.49 & 0.14 \\
\hline & $\begin{array}{l}\text { Treatment } \\
\text { (shaded) }\end{array}$ & $1.82 \pm 1.43$ & 1.27 & 0.20 \\
\hline & Phase*treatment & $0.02 \pm 0.35$ & 0.06 & 0.95 \\
\hline \multirow[t]{3}{*}{ Cape glossy starling } & Phase (B) & $-0.53 \pm 0.28$ & -1.94 & 0.05 \\
\hline & $\begin{array}{l}\text { Treatment } \\
\text { (shaded) }\end{array}$ & $0.86 \pm 0.70$ & 1.23 & 0.22 \\
\hline & Phase ${ }^{*}$ treatment & $-0.07 \pm 0.22$ & -0.31 & 0.76 \\
\hline \multirow[t]{3}{*}{ Cape turtle dove } & Phase (B) & $0.03 \pm 0.16$ & 0.21 & 0.84 \\
\hline & $\begin{array}{l}\text { Treatment } \\
\text { (shaded) }\end{array}$ & $-0.20 \pm 0.28$ & -0.72 & 0.47 \\
\hline & Phase ${ }^{*}$ treatment & $-1.11 \pm 0.17$ & -6.52 & $<0.001^{*}$ \\
\hline \multirow[t]{3}{*}{ Laughing dove } & Phase (B) & $0.13 \pm 0.11$ & 1.07 & 0.28 \\
\hline & $\begin{array}{l}\text { Treatment } \\
\text { (shaded) }\end{array}$ & $-0.44 \pm 0.69$ & -0.63 & 0.52 \\
\hline & Phase*treatment & $-0.04 \pm 0.08$ & 0.50 & 0.62 \\
\hline \multirow[t]{3}{*}{ Namaqua dove } & Phase (B) & $0.27 \pm 0.22$ & 1.24 & 0.22 \\
\hline & $\begin{array}{l}\text { Treatment } \\
\text { (shaded) }\end{array}$ & $-0.09 \pm 0.25$ & -0.37 & 0.71 \\
\hline & Phase*treatment & $-0.92 \pm 0.20$ & -4.56 & $<0.001^{*}$ \\
\hline \multirow[t]{3}{*}{ Red-headed finch } & Phase (B) & $0.04 \pm 0.20$ & 0.22 & 0.83 \\
\hline & $\begin{array}{l}\text { Treatment } \\
\text { (shaded) }\end{array}$ & $-0.84 \pm 0.44$ & -1.92 & 0.06 \\
\hline & Phase ${ }^{*}$ treatment & $0.40 \pm 0.31$ & 1.92 & 0.05 \\
\hline \multirow[t]{3}{*}{ Violet-eared waxbill } & Phase (B) & $-0.18 \pm 0.39$ & -0.47 & 0.63 \\
\hline & $\begin{array}{l}\text { Treatment } \\
\text { (shaded) }\end{array}$ & $0.02 \pm 1.11$ & 0.02 & 0.99 \\
\hline & Phase*treatment & $1.17 \pm 0.21$ & 5.59 & $<0.001^{*}$ \\
\hline \multirow{3}{*}{$\begin{array}{l}\text { White-browed sparrow- } \\
\text { weaver }\end{array}$} & Phase (B) & $1.76 \pm 0.34$ & 5.17 & $<0.001^{*}$ \\
\hline & $\begin{array}{l}\text { Treatment } \\
\text { (shaded) }\end{array}$ & $0.84 \pm 0.52$ & 1.63 & 0.10 \\
\hline & Phase*treatment & $-1.01 \pm 0.23$ & -4.34 & $<0.001^{*}$ \\
\hline \multirow{3}{*}{$\begin{array}{l}\text { Southern grey-headed } \\
\text { sparrow }\end{array}$} & Phase (B) & $0.42 \pm 0.32$ & 1.29 & 0.20 \\
\hline & $\begin{array}{l}\text { Treatment } \\
\text { (shaded) }\end{array}$ & $2.48 \pm 0.89$ & 2.77 & 0.01 \\
\hline & Phase*treatment & $-0.53 \pm 0.23$ & -2.33 & 0.02 \\
\hline
\end{tabular}




\section{Discussion}

Drinking troughs were used frequently by a wide variety of species, comprising $\sim 50 \%$ of the species commonly recorded for the region (based Southern African Bird Atlas records, Harrison et al., 1997; a proportion in keeping with another study of water use by Kalahari birds by Smit, 2013). Many of these species visited in relatively large numbers, indicating livestock watering points could be a valuable resource for parts of the avifaunal community in this arid, water scarce environment. By contrast, a study of bird visitation at natural drinking sites using camera traps in the much cooler Fynbos biome, South Africa, recorded lower bird presence, albeit also across a broad spectrum of species (Lee et al. 2017). Birds may visit water for a variety of reasons e.g. bathing for feather maintenance (Slessers 1970), although we confirmed that most visitors to these water sources were drinking, as the troughs were steep-sided and too deep for bathing.

Experimental addition of shade led to a change in temporal patterns of visitation to the drinking troughs, with a community-level shift in drinking towards the hotter mid and late afternoon compared to the early morning after shades were added. Prior to the installation of shade in our experiment, highest visitation rates had been recorded in the cooler time periods of the day (prior to midday), when air temperatures were generally below $30{ }^{\circ} \mathrm{C}$. For individual species, the shift to afternoon drinking was statistically significant only for southern grey-headed sparrow. The community-level pattern we found therefore suggests statistically undetectable (in single species models) changes in timing of drinking visits may have occurred across a wide number of species. Change in patterns of water use were accompanied by a detectable decrease in numbers of birds visiting, reflected across several of the most common species (e.g. sociable weaver, cape turtle dove, laughing dove and white-browed sparrow-weaver).

The lower numbers of birds drinking at the shaded sites during the treatment stage was unexpected, and contrasts with our prediction that higher numbers of birds would visit the shaded water points as these carried a lower risk of hyperthermia. The reason for the decrease in visitation is not clear and could arise from a combination of factors. It seems unlikely that novelty of the shade cloth stapled to the experimental shade structures was to blame, given that data were collected after a habituation period of six days. Shade cloth was stretched tightly to avoid flapping in the wind. While rain has been observed to influence drinking rates elsewhere (Lee et al. 2017), the rainfall in the experimental phase of our study was very low and the decrease in drinking rate was only seen at experimentally shaded water points. It is possible that, for most species in this study, the time spent drinking water may not be sufficient to incur significant risk of hyperthermia under the temperature 
conditions experienced (air temperatures never exceeded avian body temperatures during this study; maximum air temperature $=39 \cdot 2^{\circ} \mathrm{C}$ ).

Perhaps the most likely factor influencing the change in bird visitation rates to shaded water points was a real or perceived increase in predation risk associated with the artificial shade structures. Increased risk of predation might be a major issue when attempting to manage avian heat stress at water points in this way. Gabar goshawks (Micronisus gabar), lanner falcons (Falco biarmicus) and red-necked falcons (Falco chicquera) all regularly prey on birds drinking at Kalahari waterholes (Jenkins \& Davies 2005). Our shade cloth covers were raised approximately one metre above the lip of the drinking troughs. At this height, they might block drinking birds' view of their surroundings and make escaping an aerial attack by flight more difficult, especially for larger-bodied species. Our records of raptors in photos at our water points were very low, and we could not discern any differential change in their presence at the shaded sites; however the frame size of our photographs excluded nearby trees, from which these raptors commonly hunt. Jenkins and Davies (2005) argued that changes in bird use of water holes were likely due to environmental reasons (water availability) and not to changes in raptor predation pressure. Even so, any perceived increase in predation risk would result in birds preferring to drink at open spaces with clear views and escape routes, at all but the most thermally stressful times of day.

In this context, it may be relevant that the only species that significantly increased drinking rates in response to provision of shade was also the smallest: the violet-eared waxbill (11.8 g). Other positive (non-significant) responders included the next two smallest species in our sample, black-throated canaries $(12.7 \mathrm{~g})$ and red-headed finches $(22.7 \mathrm{~g})$. High surface area-volume ratios mean small birds are especially vulnerable to environmental heat gain (Wolf \& Walsberg 1996), and therefore might incur the greatest benefits from the provision of shade at water points. Larger birds such as cape turtle doves (130.0 g), on account of their slower heat gain per unit body mass, may have a longer window of time in which to drink before heat uptake from the environment begins to threaten thermal homeostasis. In addition, large-bodied birds require longer escape times from predators and therefore generally have longer flight initiation distances (Blumstein 2006). Larger birds also seem more likely to be targeted by raptors as they are more profitable as prey items (Cade 1965). As such, the interaction between the provision of shelter and other confounding factors, e.g. cover for aerial predators, may have been more important than the benefit of reduced risk of hyperthermia for these species.

As a management intervention, artificial provision of shade could be a potentially useful conservation tool for smaller-bodied species at highest risk of dehydration-thermoregulation 
trade-offs at high air temperatures. With careful thought, the design and placement of shade structures might be able to be improved so as to minimize perceived predation risk, thus allowing mitigation of thermal risk for small species with neutral impact on larger birds. In this study, we suspect our shaders may have been too low to allow ease of escape for larger bodied species, and could have blocked their view of predators. The obviously artificial nature of the structures may also have contributed to perceived increase in risk at shaded water points. We suggest additional studies should test new shader designs that are raised higher above the water point, to provide clearer sight lines and easier flight escape routes for birds. Shading only part of the water point could provide thermally safe spaces for small bodied species to drink while still allowing larger-bodied birds access to the open parts of the water point. Finally, constructing shaders out of materials that mimic items found in the natural environment (e.g. using tree branches or thatch) might help improve acceptance by drinking birds. Provision of artificial shade might be an avenue especially worth pursuing in in areas where operative temperature already regularly exceeds avian normothermic body temperature $\left(\sim 40^{\circ} \mathrm{C}\right.$ for most small birds, Prinzinger et al., 1991) in exposed locations such as at water points. It may also be that the importance of body mass with respect to thermoregulation will increase as climate warms (e.g. Gardner et al., 2011), and a repeat of this study design during hotter periods or in hotter places would be worthwhile.

\section{Acknowledgements}

We are grateful to the Rossouw family for allowing this study to take place on their land, and especially Willie Rossouw for help choosing suitable water points. SA received help in the field from Michelle Thompson, Sue-Joy Schultz, Tanja van de Ven and lan Thompson. We are grateful to the anonymous reviewers for providing insight that improved this manuscript, particularly with respect to the implications of the findings for conservation management.

\section{Funding}

This study was funded by the DST-NRF Centre of Excellence at the FitzPatrick Institute, University of Cape Town.

\section{Author contributions}

Designed the study: SJC, AEM, SA; fieldwork and data extraction: SA; data analyses: SJC, AL, SA; wrote manuscript sections: SJC, AEM, AL, SA; manuscript synthesis: SJC. 


\section{References}

Albright, T.P. et al., 2017. Mapping evaporative water loss in desert passerines reveals an expanding threat of lethal dehydration. Proceedings of the National Academy of Sciences, 114(9) pp.2283-2288.

Bakken, G.S., 1976. A heat transfer analysis of animals: unifying concepts and the application of metabolism chamber data to field ecology. Journal of Theoretical Biology, 60, pp.337-384.

Blumstein, D.T., 2006. Developing an evolutionary ecology of fear : how life history and natural history traits affect disturbance tolerance in birds. Animal Behaviour, 71(2) pp.389-399.

Cade, T., 1965. Relations between raptors and columbiform birds at a desert water hole. The Wilson Bulletin, 77(4), pp.340-345.

Davies, K.F. et al., 2010. Using traits of species to understand responses to land use change : Birds and livestock grazing in the Australian arid zone. Biological Conservation, 143(1), pp.78-85.

Dytham, C., 2003. Choosing and Using Statistics: a Biologist's Guide Second Edi., Oxford: Blackwell Publishing.

Ferns, P.N. \& Hinsley, S.A., 1995. Importance of topography in the selection of drinking sites by sandgrouse. Functional Ecology, 9(3), pp.371-375.

Fisher, C.D., Lindgren, E. \& Dawson, W.R., 1972. Drinking patterns and behavior of Australian desert birds in relation to their ecology and abundance. The Condor, 74(2), pp.111-136.

Gardner, J.L. et al., 2011. Declining body size: a third universal response to warming? Trends in Ecology \& Evolution, 26(6), pp.285-91.

Green, R. H. 1979. Sampling Design and Statistical Methods for Environmental Biologists, New York: Wiley.

Harrison, X.A. 2014. Using observation-level random effects to model overdispersion in count data in ecology and evolution. PeerJ 2:e616.

Harrison, J. et al. eds., 1997. The Atlas of Southern African Birds, vol. 1. Non-passerines, vol. 2. Passerines., Johannesburg: BirdLife South Africa.

Hilbe, J.M. 2011. Negative binomial regression. $2^{\text {nd }}$ Edition. Cambridge: Cambridge University Press.

IPCC, 2007. Climate change 2007: Fourth assessment report of the Intergovernmental Panel on Climate Change., Cambridge: Cambridge University Press. 
IPCC, 2011. Intergovernmental Panel on Climate Change special report on managing the risks of extreme events and disasters to advance climate change adaptation., Cambridge: Cambridge University Press.

James, C.D., Landsberg, J. \& Morton, S.R., 1999. Provision of watering points in the Australian arid zone: a review of effects on biota. Journal of Arid Environments, 41(1), pp.87-121.

Jenkins, A. \& Davies, R., 2005. Dying for a drink: running the raptor gauntlet at Kalahari waterholes. African Birdlife, August/Sep, pp.35-45.

Kruger, A. C., and S. Shongwe. 2004. Temperature trends in South Africa: 1960-2003 International Journal of Climatology, 24, pp.1929-1945.

Lee, A., Wright, D. \& Barnard, P., 2017. Hot bird drinking patterns: drivers of water visitation in a fynbos bird community. African Journal of Ecology, 55(4) pp. 541-553.

Lovegrove, B. G. 1993. The Living Deserts of Southern Africa. Fernwood Press, Vlaeberg.

Maclean, G.L., 1996. Ecophysiology of desert birds, Berlin: Springer-Verlag.

Maclean, G.L., 1983. Water transport by sandgrouse. BioScience, 33(6), pp.365-369.

McKechnie, A.E. \& Wolf, B.O., 2010. Climate change increases the likelihood of catastrophic avian mortality events during extreme heat waves. Biology Letters, 6, pp. 253-256.

Perkins, J. S. and D. S. G. Thomas. 1993. Spreading deserts or spatially confined environmental impacts? Land degradation and cattle ranching in the Kalahari Desert of Botswana. Land Degradation and Rehabilitation 4, pp.179-194.

Prinzinger, R., Pressmar, A. \& Schleucher, E., 1991. Body temperature in birds. Comparative Biochemistry and Physiology Part A: Molecular \& Integrative Physiology, 99(4), pp.499-506.

Robinson, E., Campbell, G.S. \& King, J.R., 1976. An evaluation of heat exchange in small birds. Journal of Comparative Physiology B: Biochemical, Systemic, and Environmental Physiology, 105, pp.153-166.

Skalski, J. R., and D. S. Robson 1992. Techniques for Wildlife Investigations, Design and Analysis of Capture Data, New York: Academic.

Slessers, M., 1970. Bathing behavior of land birds. The Auk, 87(1), pp.91-99.

Smit, B., 2013. Taking the heat: integrating behavioural and physiological variables to predict avian responses to climate change in the Kalahari Desert. University of Pretoria.

Whitfield, M.C. et al., 2015. Avian thermoregulation in the heat: scaling of heat tolerance and evaporative cooling capacity in three southern African arid-zone passerines. Journal of 
Experimental Biology, 218(11), pp.1705-1714.

Wolf, B.O. \& Walsberg, G.E., 1996. Thermal effects of radiation and wind on a small bird and implications for microsite selection. Ecology, 77(7), pp.2228-2236. 


\section{Appendix A}

Table A1: Complete list of bird species recorded drinking during the course of the study, and number of bird-visits by each species to watering points. Wattled starlings were not included in further analyses as they are a nomadic species and were present only during Phase B of the experiment.

\begin{tabular}{|c|c|}
\hline Species & Bird visits \\
\hline Sociable weaver & 17106 \\
\hline Cape turtle dove & 4929 \\
\hline Cape glossy starling & 4588 \\
\hline Redheaded finch & 4558 \\
\hline Southern grey-headed sparrow & 4114 \\
\hline Laughing dove & 2267 \\
\hline Wattled starling & 2216 \\
\hline Black-throated canary & 1077 \\
\hline Namaqua dove & 469 \\
\hline Violet-eared waxbill & 419 \\
\hline White-browed sparrow-weaver & 372 \\
\hline Shaft-tailed whydah & 328 \\
\hline Yellow canary & 261 \\
\hline Black-cheeked waxbill & 196 \\
\hline Fork-tailed drongo & 128 \\
\hline Kori Bustard & 88 \\
\hline Speckled pigeon & 74 \\
\hline Gabar goshawk & 61 \\
\hline Southern masked weaver & 54 \\
\hline Groundscraper thrush & 34 \\
\hline Redfaced mousebird & 27 \\
\hline Lilac-breasted roller & 24 \\
\hline Crowned lapwing & 21 \\
\hline Cape sparrow & 18 \\
\hline Black-chested prinia & 16 \\
\hline Fawn-coloured lark & 16 \\
\hline Golden-tailed woodpecker & 13 \\
\hline Spotted thickknee & 11 \\
\hline Green winged pytilia & 5 \\
\hline Marico flyctcher & 4 \\
\hline Red-eyed bulbul & 4 \\
\hline Southern pale chanting goshawk & 4 \\
\hline Familiar chat & 2 \\
\hline Acacia pied barbet & 1 \\
\hline Kalahari scrub-robin & 1 \\
\hline Scaly-feathered finch & 1 \\
\hline SUM & 43507 \\
\hline
\end{tabular}


Table A2: Comparison of pattern of visitation (mean visitation rates per hour per experimental phase) to watering points by Kalahari Desert birds during five time periods across the course of the day: 06h00-07h00, 09h00-10h00, 12h00-13h00, 15h00-16h00, 18h00-19h00. N = 419 hours of observations over 16 days ( 10 days during Phase A, 6 days during Phase $B$ ) at 6 watering points ( 3 control and 3 experimental). Experimental watering points were unshaded during Phase $A$ but shaded during Phase $B$ of the experiment, control watering points remained unshaded throughout. A Bonferroni correction was applied, and $p$-values $<0.001$ were considered statistically significant and are marked with*.

\begin{tabular}{|c|c|c|c|}
\hline Species & Watering points compared & $x^{2}$ & $p$-value \\
\hline \multirow[t]{4}{*}{ All } & Phase A control: Phase A experimental & 3.24 & 0.5183 \\
\hline & Phase A control: Phase B control & 20.36 & $0.0004^{*}$ \\
\hline & Phase A experimental: Phase B experimental & 45.34 & $0.0000^{*}$ \\
\hline & Phase B control: Phase B experimental & 33.09 & $0.0000^{*}$ \\
\hline \multirow{4}{*}{$\begin{array}{l}\text { Southern grey- } \\
\text { headed sparrow }\end{array}$} & Phase A control: Phase A experimental & 11.10 & 0.0255 \\
\hline & Phase A control: Phase B control & 8.78 & 0.0670 \\
\hline & Phase A experimental: Phase B experimental & 25.12 & $0.0000^{*}$ \\
\hline & Phase B control: Phase B experimental & 2.92 & 0.5711 \\
\hline \multirow{4}{*}{$\begin{array}{l}\text { Black-throated } \\
\text { canary }\end{array}$} & Phase A control: Phase A experimental & 46.14 & $0.0000^{*}$ \\
\hline & Phase A control: Phase B control & 6.95 & 0.1385 \\
\hline & Phase A experimental: Phase B experimental & 2.15 & 0.7079 \\
\hline & Phase B control: Phase B experimental & 8.07 & 0.0892 \\
\hline \multirow{4}{*}{$\begin{array}{l}\text { Cape glossy } \\
\text { starling }\end{array}$} & Phase A control: Phase A experimental & 3.22 & 0.5221 \\
\hline & Phase A control: Phase B control & 10.13 & 0.0383 \\
\hline & Phase A experimental: Phase B experimental & 14.78 & 0.0052 \\
\hline & Phase B control: Phase B experimental & 3.27 & 0.5139 \\
\hline \multirow[t]{4}{*}{ Cape turtle-dove } & Phase A control: Phase A experimental & 8.46 & 0.0762 \\
\hline & Phase A control: Phase B control & 3.60 & 0.4635 \\
\hline & Phase A experimental: Phase B experimental & 0.76 & 0.9434 \\
\hline & Phase B control: Phase B experimental & 4.58 & 0.3329 \\
\hline \multirow[t]{4}{*}{ Laughing dove } & Phase A control: Phase A experimental & 1.92 & 0.7499 \\
\hline & Phase A control: Phase B control & 3.70 & 0.4487 \\
\hline & Phase A experimental: Phase B experimental & 0.83 & 0.9341 \\
\hline & Phase B control: Phase B experimental & 2.21 & 0.6978 \\
\hline \multirow[t]{4}{*}{ Namaqua dove } & Phase A control: Phase A experimental & 0.80 & 0.9386 \\
\hline & Phase A control: Phase B control & 1.36 & 0.8504 \\
\hline & Phase A experimental: Phase B experimental & 0.74 & 0.9467 \\
\hline & Phase B control: Phase B experimental & 1.58 & 0.8120 \\
\hline \multirow[t]{4}{*}{ Red-headed finch } & Phase A control: Phase A experimental & 2.60 & 0.6263 \\
\hline & Phase A control: Phase B control & 0.77 & 0.9428 \\
\hline & Phase A experimental: Phase B experimental & 3.59 & 0.4638 \\
\hline & Phase B control: Phase B experimental & 7.42 & 0.1153 \\
\hline \multirow[t]{4}{*}{ Sociable weaver } & Phase A control: Phase A experimental & 7.75 & 0.1012 \\
\hline & Phase A control: Phase B control & 11.28 & 0.0236 \\
\hline & Phase A experimental: Phase B experimental & 16.57 & 0.0023 \\
\hline & Phase B control: Phase B experimental & 17.06 & 0.0019 \\
\hline
\end{tabular}




\begin{tabular}{llll}
\hline Violet-eared & Phase A control: Phase A experimental & 0.44 & 0.9795 \\
waxbill & Phase A control: Phase B control & 1.63 & 0.8041 \\
& Phase A experimental: Phase B experimental & 0.79 & 0.9403 \\
White-browed & Phase B control: Phase B experimental & 3.99 & 0.4076 \\
sparrow-weaver & Phase A control: Phase A experimental & 0.69 & 0.9521 \\
& Phase A control: Phase B control & 5.06 & 0.2808 \\
& Phase A experimental: Phase B experimental & 0.44 & 0.9794 \\
& Phase B control: Phase B experimental & 0.52 & 0.9720 \\
\hline
\end{tabular}

*statistically significant $(p<0.001)$

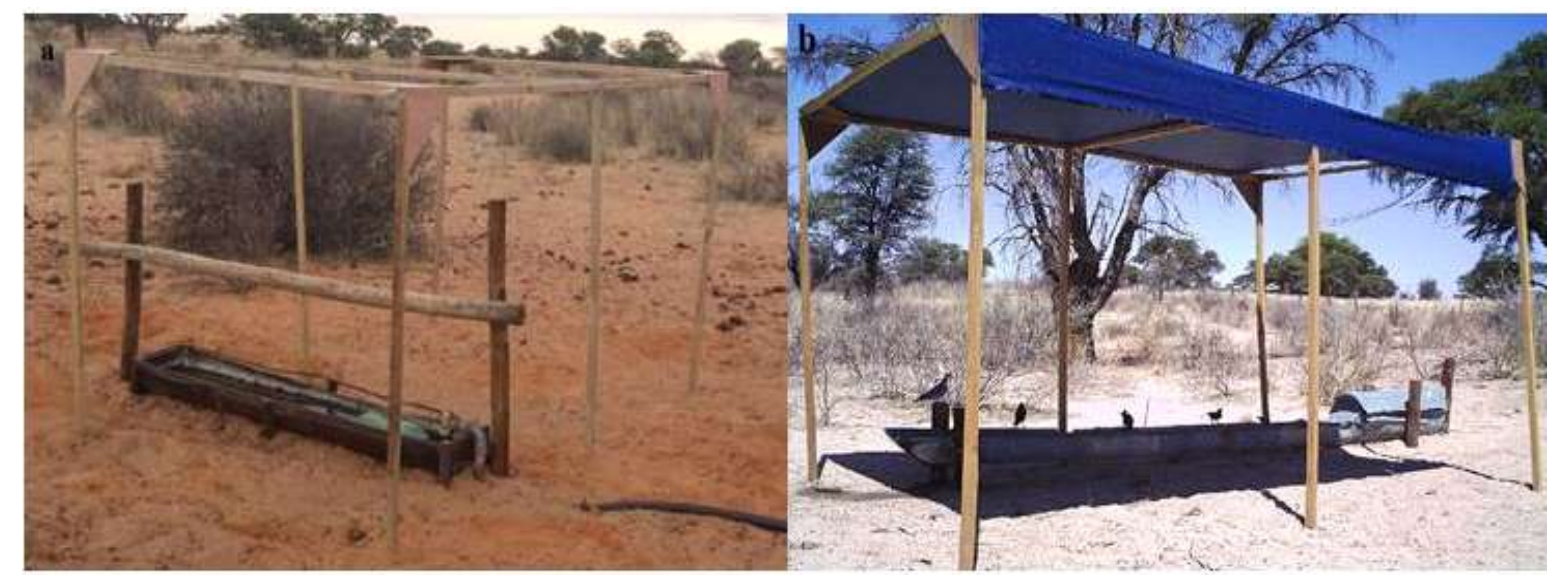

Figure A1: (a) wooden frame at a watering point without shade added; (b) wooden frame with shade-cloth added. 